\title{
A Critical Review of Power Quality Standards and Definitions applied to DC Microgrids
}

\author{
Giel Van den Broeck, Jeroen Stuyts, Johan Driesen \\ KU Leuven - EnergyVille \\ Thor Park 8310 \\ 3600 Genk \\ Belgium
}

\begin{abstract}
As compared to AC microgrids, DC microgrids reduce the hardware complexity of converter-dominated power distribution in the presence of a high number of renewable energy sources, energy storage systems and energy efficient loads. Another frequently highlighted advantage is their resiliency and tolerance against $\mathrm{AC}$ grid disturbances resulting in improved overall power quality. However, with respect to power quality, the question arises whether existing international power quality standards and metrics remain applicable in DC microgrids or require adjustments. Therefore, this paper critically revises the definitions and power quality indicators specified in IEC 61000 and IEEE Std1159. The resulting review is essential to unambiguously define the responsibilities of the microgrid operators, customers and device manufacturers. Apart from that, causes and consequences of power quality issues in DC microgrids are discussed.
\end{abstract}

Keywords: Power Quality, DC, Microgrid

Email address: giel.vandenbroeck@esat.kuleuven.be (Giel Van den Broeck) 


\section{Introduction}

Considering the increasing number of distributed generation, electric vehicles, energy storage and energy efficient loads that inherently generate or consume DC power, DC microgrids $(D C \mu G)$ offer a promising alternative to the AC counterpart [1]. The improved compatibility between the DC devices and a DC power backbone reduces and simplifies the power conversion steps, thereby reducing the power conversion losses and increasing the component-level reliability [1]. Efficiency gains in the range of 12 to $18 \%$ have been reported [2]. Apart from the improved compatibility, $D C \mu G$ enable to transfer more power per conductor cross-section [3] and allow to actively control the device currents by means of the switch-mode DC-DC converters that interface the DC devices with the network. Applications considered are electric vehicle charging stations [4] and other charging applications [5].

Increased power quality is often highlighted as a distinguishing feature of DC microgrids [6]. Because the DC voltage is tightly controlled, in part by $\mathrm{AC} / \mathrm{DC}$ converters connected to an overlay $\mathrm{AC}$ grid, the $D C \mu G$ is more tolerant against AC side disturbances [7]. Power quality is thus highly intertwined with voltage stability, as the DC voltage is a metric for the power balance in the system and needs active stabilization [8]. But it is unlikely that high levels of power quality remain assured when multi-vendor $D C \mu G$ will develop, each adhering to their own guidelines and requirements. Standardization is frequently mentioned as a hurdle for the wide-scale deployment of $D C \mu G[9]$. An important part of standardization encompasses power quality standards and metrics, required for ensuring interoperability and assigning quantifiable responsibilities. 
Available literature regarding power quality in $D C \mu G$ primarily focuses on solutions addressing specific power quality issues. A first solution focuses on reducing voltage oscillations by implementing active damping [10]. Alternatively, voltage oscillations are reduced by implementing nonlinear controllers [11]. Another solution applies converter interleaving to reduce the voltage ripple in the network [12]. Nuutinen et al. have investigated common-mode and radio-frequency electromagnetic interference due to pulse-width modulated inverters in a public distribution low-voltage DC (LVDC) research site [13. Although the proposed solutions definitely enhance the power quality of $D C \mu G$, it remains unclear what is required from the system-level perspective.

From the system-level point-of-view, Magro et al. proposed DC power quality indices for low-frequency sinusoidal disturbances and voltage ripple [14, 15]. Whaite et al. have addressed interharmonics and the impact of fault and inrush currents on the voltage in $D C \mu G$ [16]. However, there remains a need to critically review whether existing power quality standards are applicable to $D C \mu G$ or require adjustments.

Therefore, the present work serves as a starting point by revisiting the current international power quality standards IEC 61000 and IEEE Std1159. The paper thereby excludes radiated phenomena, electrostatic discharge and nuclear electromagnetic pulse as classified by IEC 61000 [17]. The aim is to revise the current power quality framework and verify its applicability to $D C \mu G$, targeting all stakeholders that should address particular issues listed in this paper.

This paper is structured as follows: the next section revisits the concept of power quality as defined by different international standards and verifies the applicability of the definitions to $D C \mu G$. The third section presents a 
classification of DC power quality issues, its causes and its consequences. As some power quality issues in DC are less understandable, the fourth section will present simulation results as an example. The last section concludes this paper.

\section{Power quality definitions}

The first concern when dealing with power quality is the availability of a proper definition that is sufficiently general to encompass both AC and DC power quality. The definition provided by the IEC 61000 is suited in that sense as it makes no distinction between $\mathrm{AC}$ and DC power quality when stating that "Power quality encompasses the characteristics of the electricity at a given point on an electrical system, evaluated against a set of reference technical parameters" [17. Other references provide different definitions for power quality, but none of them makes a distinction between $\mathrm{AC}$ and DC power quality:

- Power quality is the combination of voltage quality and current quality. Thus power quality is concerned with deviations of voltage and/or current from the ideal waveform [18].

- Any power problem manifested in voltage, current, or frequency deviations that results in failure or misoperation of customer equipment [19.

- Power quality is the concept of powering and grounding sensitive equipment in a matter that is suitable to the operation of that equipment and compatible with the premise wiring system and other connected equipment [20]. 


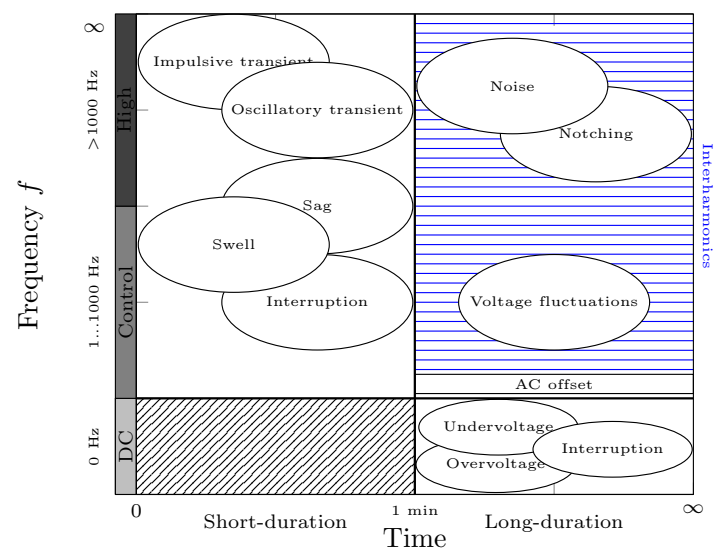

Figure 1: Time-frequency classification of DC power quality issues

On the other hand, the IEEE recommended practice Std1709 addresses $1 \mathrm{kV}$ to $35 \mathrm{kV}$ medium-voltage DC (MVDC) distribution systems and defines power quality as "compliance with specified voltage tolerances and voltage ripple" [21]. That definition clearly narrows down power quality to voltage quality, which is a fundamental characteristic of DC power distribution systems as the DC voltage is a distributed measure of the power balance in DC power distribution systems.

\section{DC power quality issues}

Fig. 1 classifies the power quality issues that are conceivable within DC distribution systems based upon the duration of the phenomenon (time axis) and the frequency content of the voltage waveform (frequency axis). The time axis is subdivided between short-duration, transient phenomena and long-duration, steady-state phenomena. The frequency axis in turn is subdivided in high-frequency components (typically in the range of the switching frequency $1 \mathrm{kHz}$ and above), components in the order of magnitude of the 
control bandwidth of the voltage controllers present within the $D C \mu G$ and in DC components. The power quality issues that will be subsequently discussed are also summarized in Table 1, including the indicators to quantify them, possible causes and consequences. 
Table 1: DC power quality issues (based upon [22, 23])

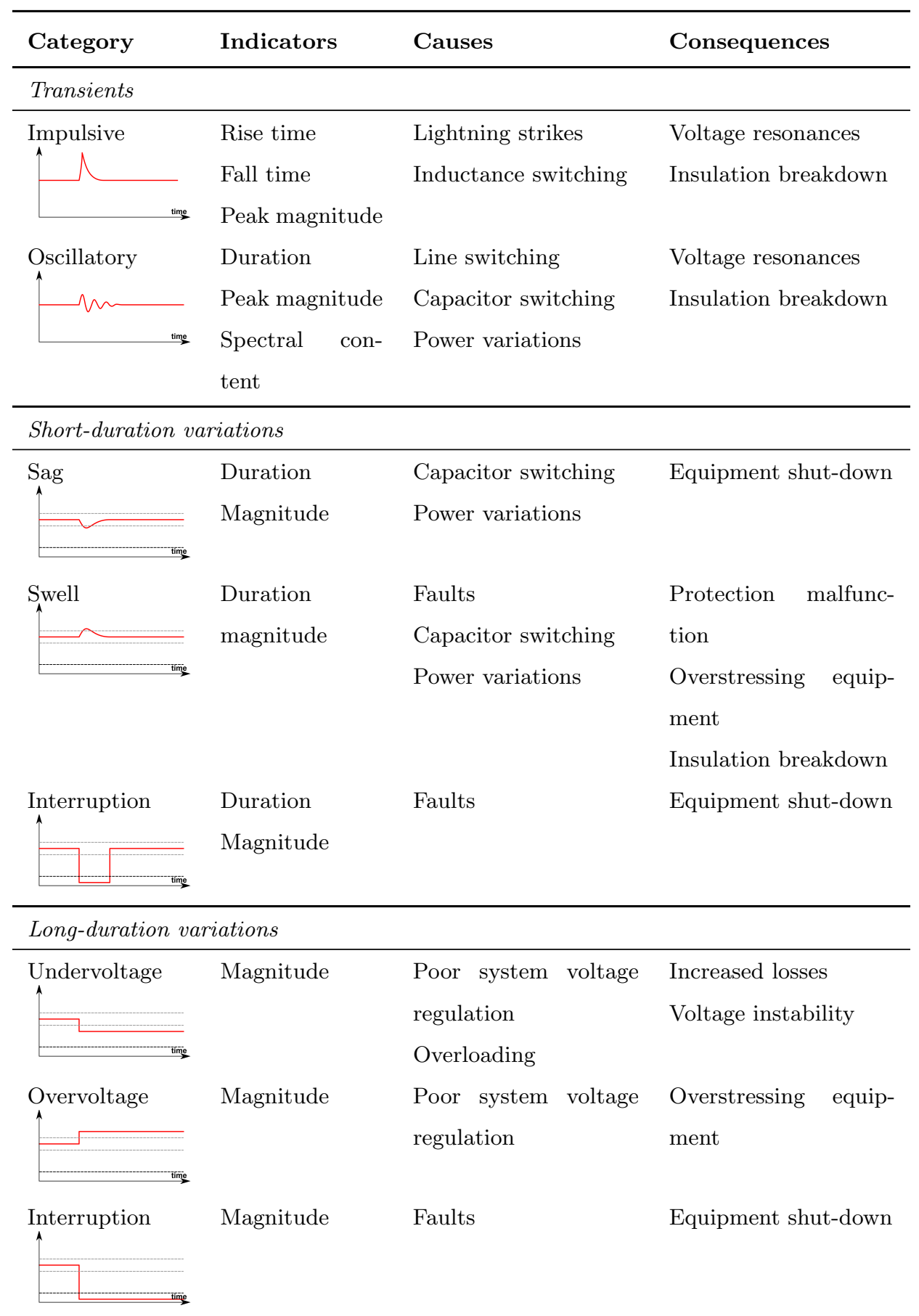


Table 1: DC power quality issues (continued)

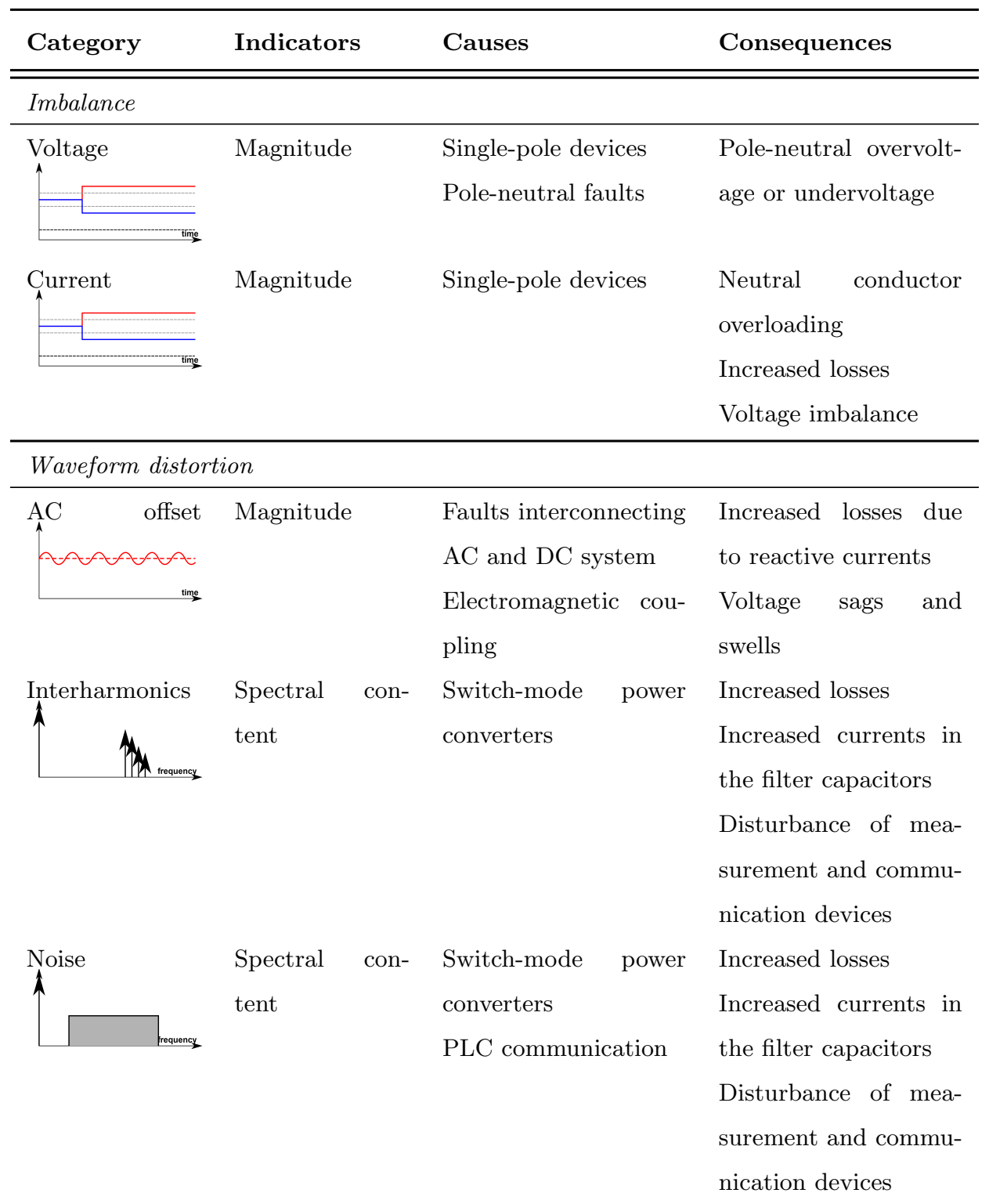


Table 1: DC power quality issues (continued)

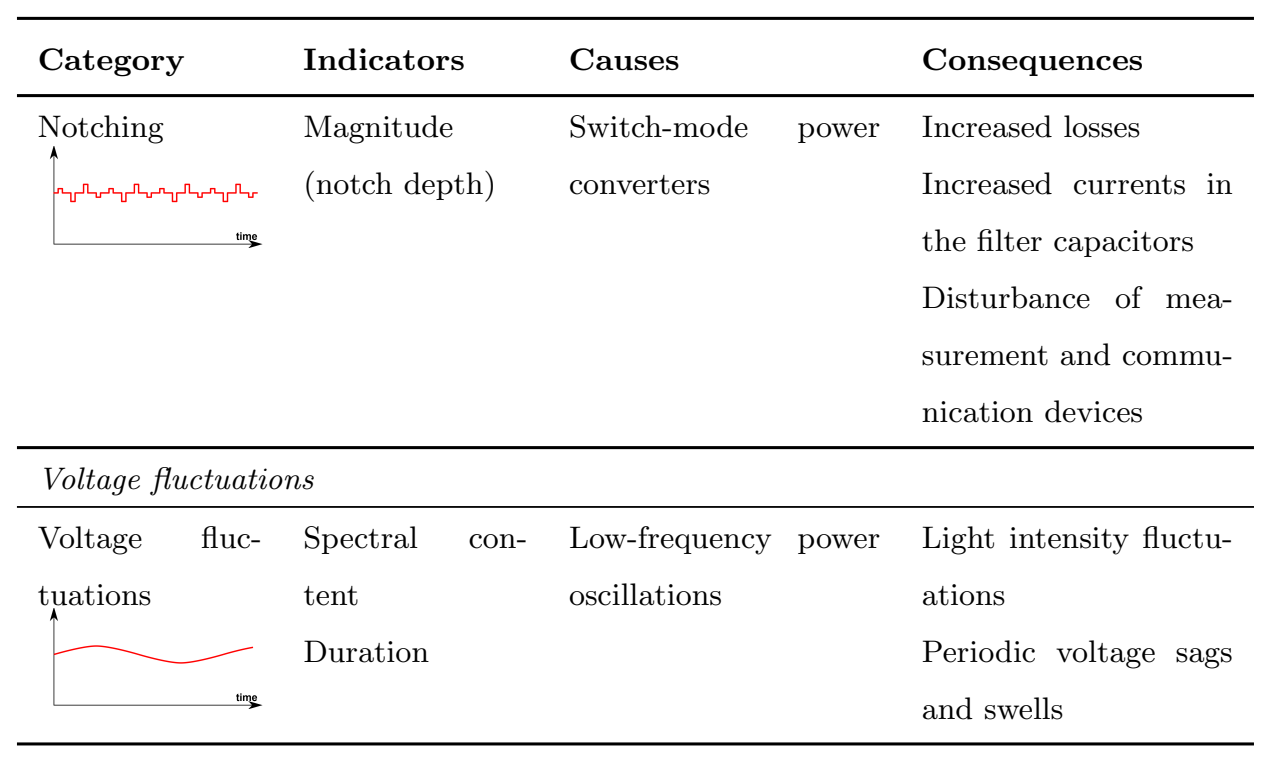

\subsection{Transients}

According to the IEEE Std1159 [22], impulsive transients are sudden, nonpower frequency changes from the nominal condition of voltage, current, or both that are unidirectional in polarity. Accordingly, oscillatory transients are sudden, nonpower frequency changes in the steady-state condition of voltage, current, or both, that include both positive and negative polarity values. The impulsive transients are characterized by their rise time, fall time and peak magnitude, while oscillatory transients are characterized by their frequency spectrum and duration. In IEEE Std1159 [22], low-frequency $(<5 \mathrm{kHz})$, medium frequency $(5-500 \mathrm{kHz})$ and high-frequency $(0.5-5 \mathrm{MHz})$ oscillatory transients are distinguished. Similarly, the EN50160 [24] defines transient overvoltage as a short duration oscillatory or non-oscillatory overvoltage usually highly damped and with a duration of a few milliseconds or less. According to IEC61000 (Annex A.3) [17] a transient designates "a phe- 
nomenon or a quantity which varies between two consecutive steady states during a time interval short when compared with the time-scale of interest". The proposed definitions are equally applicable to $D C \mu G$.

Impulsive and oscillatory transients in $D C \mu G$ are possibly caused by lightning strikes or sudden switching operations causing induced voltages. They typically occur beyond the frequency range of the controller bandwidth. This may cause insulation breakdown or trigger system resonances.

\subsection{Short- and long-duration variations}

Voltage variations in $D C \mu G$ may be categorized based upon their duration, magnitude and direction of change, similar to the IEEE Std1159 [22]. Short-term and long-term variations are distinguished, primarily based upon the underlying causes. Short-term variations are caused by switching operations, faults and large power fluctuations on the system, while long-term variations occur in steady-state due to power flow variations. An arbitrary boundary of one minute is used in practice for $\mathrm{AC}$ to distinguish both and a further categorization in terms of instantaneous, momentary and temporary variations is made [22].

Based on the direction of change and their magnitude, three rms voltage variations may occur: sags, swells and interruptions. According to IEEE Std1159 [22], a sag is defined as "a decrease in rms voltage between 0.1 and 0.9 p.u. for durations from 0.5 cycles up to 1 minute". A swell is defined as "an increase in rms voltage above 1.1 p.u for durations from 0.5 cycles up to 1 minute". An interruption is defined as "a decrease in rms voltage below 0.1 p.u. for durations from 0.5 cycles and 1 minute". For durations longer than 1 minute, the IEEE Std1159 [22] defines the subcategories undervoltage, overvoltage and sustained interruption, i.e. the long-duration 
variants of sags, swells and interruptions. The same magnitude levels apply as for short-duration variations.

While the IEEE Std1159 [22] include rms in the respective definitions, the IEC61000 [17] does not. A voltage dip (synonym of sag) is "a temporary reduction of the voltage at a point in the electrical system below a threshold". A voltage swell is defined as "a temporary increase of the voltage at a point in the electrical system above a threshold". Interruption and voltage dip share the same definition, although the threshold level for an interruption is lower. The IEC61000 standard does not define the concepts of overand undervoltage as the IEEE Std1159 does for steady-state deviations.

The EN50160 24] adopts similar definitions, but specifies the 0.9 and 1.1 p.u. threshold levels for voltage dips and swells respectively. A supply interruption is defined as "a condition in which the voltage at the supply terminals is lower than $5 \%$ of the reference voltage". Furthermore, it sets the boundary between short- and long-term interruptions at $3 \mathrm{~min}$. Note that the presented definitions are also applicable to DC power distribution systems without reformulation, although the threshold levels may be a subject for further discussion. The Finish SFS-6000 standard for instance limits the $\mathrm{DC}$ voltage in the $-25 \%$ to $+10 \%$ range relative to its nominal value [25].

Voltage sags and swells in $D C \mu G$ are caused by capacitor switching as the front-end of the dc-dc converters in the network generally contain filter capacitors, equipment turn-on and turn-off and faults. Interruptions occur primarily in a disconnected section following a fault. Similarly, under- and overvoltages are caused by power variations or as a consequence of poor voltage regulation. Voltage swells and overvoltages are considered to have a more detrimental impact on the equipment operation as system infrastructure (dc-dc converters, cable infrastructure) may experience irreversible 
insulation breakdown. On the contrary, voltage sags and undervoltage may trigger devices to shut-down and disconnect, which has an impact on the system's availability. Furthermore, increased losses may occur in case of undervoltage, because the current levels increase to distribute the same amount

of power. Another consequence of undervoltage is voltage instability in the presence of constant power loads, as the stability margins decrease [11].

When considering bipolar DC distribution networks, that adopt a threewire (positive-neutral-negative) configuration [26, 27], a voltage sag or swell can also be the consequence of a load decrease or increase respectively, opposite to what one would expect. Voltage sags or undervoltage may for instance occur between the positive pole and the neutral in case loads are turned off that are connected between the neutral and negative pole and vice versa. Similarly, voltage swells may occur following a fault in the other pole.

\subsection{Imbalance}

\subsubsection{Voltage imbalance}

In three-phase AC systems, voltage imbalance is characterized by the voltage unbalance factor (i.e. the ratio between the negative- or zerosequence and positive-sequence voltage) which is limited to 2\% in EN50160 [24] and 3\% in IEEE Std1159 [22]. The IEC61000 [17] adopts the same definitions.

In bipolar $D C \mu G$, a similar phenomenon may occur in case devices are connected between the poles and neutral conductor, similar to single-phase devices in three-phase AC systems. Alternatively, voltage imbalance may be caused by pole-to-neutral faults.

The decomposition into balanced and unbalanced components of voltages 
and currents in bipolar $D C \mu G$ [27, 28] enables to define a voltage unbalance factor $V U F$ in (1) as the ratio between the unbalanced and balanced voltage at a certain node in the network.

$$
V U F \equiv \frac{V_{U}}{V_{B}}=\frac{V_{p}-V_{n}}{V_{p}+V_{n}}
$$

where $V_{p}$ is the positive pole-to-neutral voltage, $V_{n}$ is the neutral-tonegative pole voltage, $V_{U} \equiv \frac{V_{p}-V_{n}}{2}$ is the unbalanced voltage and $V_{B} \equiv \frac{V_{p}+V_{n}}{2}$ is the balanced voltage.

For three-phase AC constraining the VUF is essential in the presence of three-phase AC machines without active front-end as negative sequence components increase the thermal loading of the machine [29]. However, in bipolar $D C \mu G$, devices function correctly as long as the pole-to-neutral voltage constraints are respected as defined in the short- and long-duration variations. A specific VUF constraint thus becomes obsolete.

\subsubsection{Current imbalance}

Current imbalance causes currents in the neutral conductor, potentially overloading it and triggering overcurrent protective devices. Parallel to the definition of balanced and unbalanced voltages, current imbalance in the network cable can be characterized by the unbalanced current $I_{U}$ in (2).

$$
I_{U} \equiv \frac{I_{p}-I_{n}}{2}
$$

where $I_{p}$ is the current drawn from the positive pole by a device connected between the positive pole and the neutral and $I_{n}$ is the current drawn from the negative pole by a device connected between the neutral and negative pole. 
$I_{U}$ is related to the neutral conductor current, depending on the network configuration. For example, in case of a radial network, $I_{U}$ represents twice the neutral conductor current. Attention should be paid in case a net amount of current is injected in the positive pole and withdrawn from the negative pole and vice versa. In that condition, up to twice the nominal pole conductor current may flow in the neutral conductor.

\subsection{Waveform distortion}

\subsubsection{AC offset}

Power frequency $\mathrm{AC}$ voltage waveforms can appear superimposed on the DC voltage level due to unintended galvanic or magnetic coupling between the $\mathrm{AC}$ and the $D C \mu G[30$. While DC offset in AC may cause transformer saturation and associated heating and stressing of the insulation [22], an AC offset in $D C \mu G$ leads to reactive currents in the network causing additional losses and possibly intolerable voltage variations.

The amplitude of the power frequency component (50 or $60 \mathrm{~Hz}$ ) relative to the fundamental DC voltage component is a measure to quantify AC offset in $D C \mu G$. As long as the magnitude remains limited to the voltage constraints specified for short- and long-duration variations, the $\mathrm{AC}$ power frequency component is likely to be filtered by the DC-DC point-of-load converters regulating the output voltage at the end-device hence causing no loss of operation. However increased losses in the distribution system remain a motivation to impose a limitation.

\subsubsection{Interharmonics and noise}

As harmonics are defined as "sinusoidal waveforms having frequencies that are integer multiples of the power frequency" [22], hamonics by definition do not exist in DC distribution systems. All distinct sinusoidal 
waveforms that may occur in $D C \mu G$ are consequently classified as interharmonics, i.e. not integer multiples of the power frequency [22]. Interharmonics may be caused by switch-mode converters that inject current at their respective switching frequency and harmonic components of the switching frequency due to pulse-width modulation.

Interharmonics cause additional losses in the filter capacitors and may disturb communication signals and measurement devices [31]. For example, interharmonics may impact the proper operation of arc-fault detection devices and residual current devices. Moreover, interharmonics increase the conduction losses.

While interharmonics in $\mathrm{AC}$ occur generally at frequencies in the range of the power frequency, interharmonics in $D C \mu G$ may also occur at significantly higher frequencies near the switching frequency in the 1-100 kHz range and higher with the advent of wide-bandgap power semiconductors [32, 33]. Hence, the distinction between noise (spectral content typically lower than $200 \mathrm{kHz}$ ) becomes less strict. As also the consequences of noise and (switching) interharmonics coincide, a distinction between both phenomena may have no further relevance. A recent example where interharmonics appear, are bipolar DC networks powered by a neutral-point clamped inverter [34].

Mariscotti et al. recognized that interharmonics are closely related to voltage and current ripple, which they propose to quantify using the ripple index as defined in (3) for a sampled voltage or current signal $q[n]$ [14, 15].

$$
q_{p p, T}=\max _{n, k \geq 0}\left(q[n]-q\left[n+k_{T}+k\right]\right)
$$

where $q_{p p, T}$ equals the peak-to-peak ripple index evaluated over the time window $T, q[n]$ is the sampled voltage or current signal with index $n, k$ is a 
positive integer, $k_{T}=\left\lceil\frac{T}{\Delta t}\right\rceil$ and $\Delta t$ is the sample period.

It has been shown that the peak-to-peak ripple index can be evaluated using analog filtering or a discrete fourier transform [15]. Furthermore, the authors propose to evaluate the peak-to-peak ripple for three different time windows $T$, namely $T=6.7 \mu \mathrm{s}, T=50 \mu \mathrm{s}$ and $T=500 \mu \mathrm{s}$ to account for different ripple frequencies in the $2 \mathrm{kHz}$ and $150 \mathrm{kHz}$ range, caused by large and small power electronic converters respectively.

Alternatively, the relative peak-to-peak ripple may be defined as in (4) 35 .

$$
q_{p p, T}=\frac{q\left[n_{\max }\right]-q\left[n_{\min }\right]}{q_{d c}}
$$

where $q\left[n_{\max }\right]$ and $q\left[n_{\min }\right]$ are respectively the maximum and minimum values of the sampled signal $q[n]$ observed over the time window $T$ and $q_{d c}$ is the $\mathrm{DC}$ value of the sampled signal over the time window $T$.

\subsubsection{Notching}

IEEE Std1159 defines voltage notching as "a periodic voltage disturbance caused by the normal operation of power electronics devices when current is commutated from one phase to another" [22]. Alternatively, IEEE Std519 defines a notch as "a switching (or other) disturbance in the normal voltage waveform, lasting less than 0.5 cycles, which is initially of opposite polarity than the waveform and is thus subtracted from the normal waveform in terms of the peak value of the disturbance voltage" [31]. Clearly, those definitions are based upon the underlying cause of voltage notches in $\mathrm{AC}$, namely the commutation from one phase to another in power electronic converters [22, 36]. Voltage notches in AC have been reported to excite the natural frequencies of the system and to cause parallel resonances, poten- 
tially causing overvoltage stress [36]. Compatibility levels for $\mathrm{AC}$ have been established in IEC61000-2-2 [37].

Notching is characterized by the notch depth and the duration. It is caused by switch-mode dc-dc converters with insufficient capacitance at the front-end as will be exemplified in the next section.

\subsection{Voltage fluctuations}

Voltage fluctuations in AC distribution systems lead to low-frequency light intensity oscillations that discomfort human beings, a phenomenon referred to as flicker [22]. IEC61000 defines flicker as "Impression of unsteadiness of visual sensation induced by a light stimulus whose luminance of spectral distribution fluctuates with time" [17]. On the other hand, voltage fluctuations may cause periodic peak voltages that outreach the tolerable voltage range.

The voltage fluctuations result from low-frequency power fluctuations, subsequently causing DC voltage fluctuations. Similarly, DC voltage fluctuations may also result from providing reactive power and other ancillary services to the overlay AC grid [38].

In $\mathrm{AC}$, voltage fluctuations are quantified using the short-term and longterm flicker severity index, which quantifies how flicker is perceived by human beings through a series of sensitivity functions originating from a rms voltage measurement [39]. The sensitivity functions have been specifically established for incandescent light bulbs and hence are not applicable to other lighting sources such as LED or fluorescent lighting.

The question arises whether these voltage fluctuations will have noticeable impact as lighting fixtures are increasingly converter-interfaced, a discussion which is both relevant in $\mathrm{AC}$ and $D C \mu G$. For example, it has been 
concluded that led drivers equipped with DC-DC converters, that control the output current to maintain the luminous flux, show higher immunity to superimposed AC voltage variations [40]. Therefore the practical relevance of voltage flicker is subject for debate, both in $\mathrm{AC}$ and $D C \mu G$.

\subsection{AC power quality issues not present in $D C$}

The previous discussion has shown that the power quality issues, originally defined from an $\mathrm{AC}$ perspective, are also relevant in $D C \mu G$. However, harmonics [21] and power frequency variations disappear in the DC context.

\subsection{Summary}

To summarize this section, consider Table 2, which indicates for each power quality issue:

- Whether the issue appears in $D C \mu G(\mathbf{\bullet})$ or not ( $\square)$.

- Whether a definition is available and appropriate for $D C \mu G(\boldsymbol{})$, is undefined $(\boldsymbol{X})$, or requires reconsideration $(\Delta)$.

- Whether an indicator is available and appropriate for $D C \mu G(\boldsymbol{\checkmark})$, is undefined $(\boldsymbol{x})$, or requires reconsideration $(\Delta)$.

\section{Simulation results}

Some power quality issues, their causes and consequences are less clearcut and will therefore be illustrated in the simulation of a half-bridge and neutral-point clampes (NPC) converter depicted in Fig. 2. The half-bridge converter is supplied from a unipolar voltage source $v_{s}=400 \mathrm{~V}$ via the line resistance $R_{l}=0.1 \Omega$ and drives a constant current load of $I_{L}=100 \mathrm{~A}$. The 
Table 2: Status of current standardization of power quality issues in $D C \mu G$

\begin{tabular}{|c|c|c|c|c|c|c|}
\hline \multirow[t]{2}{*}{ Power Quality issue } & \multirow[t]{2}{*}{$\mathrm{AC}$} & \multirow[t]{2}{*}{$\mathrm{DC}$} & \multicolumn{2}{|c|}{ IEC 61000} & \multicolumn{2}{|c|}{ IEEE Std1159 } \\
\hline & & & Definition & Indicator & Definition & Indicator \\
\hline Power frequency variations & $\mathbf{\square}$ & $\square$ & $\square$ & $\square$ & $\square$ & $\square$ \\
\hline \multicolumn{7}{|l|}{ Transients } \\
\hline Impulsive/Surge & $\mathbf{\square}$ & $\mathbf{\square}$ & $\checkmark$ & $\checkmark$ & $\checkmark$ & $\checkmark$ \\
\hline Oscillatory & $\mathbf{\square}$ & $\mathbf{\square}$ & $x$ & $x$ & $\checkmark$ & $\checkmark$ \\
\hline \multicolumn{7}{|l|}{ Short-duration variations } \\
\hline Sag/Dip & $\mathbf{\square}$ & $\mathbf{\square}$ & $\checkmark$ & $\checkmark$ & $\checkmark$ & $\checkmark$ \\
\hline Swell & $\mathbf{\square}$ & $\mathbf{\square}$ & $\checkmark$ & $\checkmark$ & $\checkmark$ & $\checkmark$ \\
\hline Interruption & $\mathbf{\square}$ & $\mathbf{\square}$ & $\checkmark$ & $\checkmark$ & $\checkmark$ & $\checkmark$ \\
\hline \multicolumn{7}{|l|}{ Long-duration variations } \\
\hline Undervoltage & $\mathbf{\square}$ & $\mathbf{\square}$ & $x$ & $x$ & $\checkmark$ & $\checkmark$ \\
\hline Overvoltage & $\mathbf{\square}$ & $\mathbf{\square}$ & $x$ & $x$ & $\checkmark$ & $\checkmark$ \\
\hline Interruption & $\boldsymbol{\square}$ & $\mathbf{\square}$ & $\checkmark$ & $\checkmark$ & $\checkmark$ & $\checkmark$ \\
\hline \multicolumn{7}{|l|}{ Imbalance } \\
\hline Voltage & $\mathbf{\square}$ & $\mathbf{\square}$ & $\Delta$ & $\Delta$ & $\Delta$ & $\Delta$ \\
\hline Current & $\mathbf{\square}$ & $\mathbf{\square}$ & $\Delta$ & $\Delta$ & $\Delta$ & $\Delta$ \\
\hline \multicolumn{7}{|l|}{ Waveform distortion } \\
\hline AC offset & $\square$ & $\mathbf{\square}$ & $x$ & $x$ & $x$ & $x$ \\
\hline DC offset & $\mathbf{\square}$ & $\square$ & $\square$ & $\square$ & $\square$ & $\square$ \\
\hline Harmonics & $\mathbf{\square}$ & $\square$ & $\square$ & $\square$ & $\square$ & $\square$ \\
\hline Interharmonics & $\boldsymbol{\square}$ & $\mathbf{\square}$ & $\checkmark$ & $\checkmark$ & $\checkmark$ & $\checkmark$ \\
\hline Noise & $\boldsymbol{\square}$ & $\mathbf{\square}$ & $x$ & $x$ & $\checkmark$ & $\checkmark$ \\
\hline Notching & $\mathbf{\square}$ & $\mathbf{\square}$ & $x$ & $x$ & $\checkmark$ & $\checkmark$ \\
\hline \multicolumn{7}{|l|}{ Voltage fluctuations } \\
\hline Voltage fluctuations & $\mathbf{\square}$ & $\mathbf{\square}$ & $\checkmark$ & $\Delta$ & $\checkmark$ & $\Delta$ \\
\hline Legend & \multicolumn{6}{|c|}{$\begin{array}{l}\text { Issue applicable in } D C \mu G \square \text { Issue not applicable in } D C \mu G \\
\checkmark \text { Definition/indicator is available and applicable } \\
\Delta \text { Current definition/indicator requires reconsideration } \\
x \text { No definition/indicator defined }\end{array}$} \\
\hline
\end{tabular}




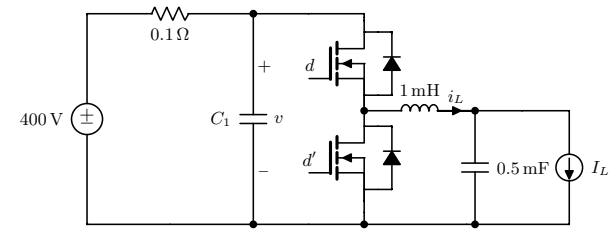

(a) Half-bridge

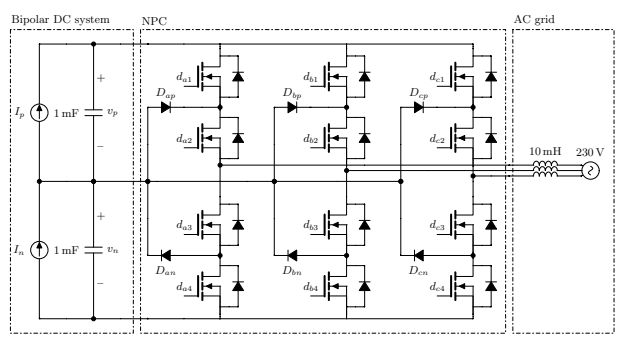

(b) Neutral-point clamped circuit

Figure 2: Simulated circuits

converter operates at a constant switching frequency of $16 \mathrm{kHz}$. The NPC also operates at $16 \mathrm{kHz}$ and connects a bipolar DC system to an overlay AC grid.

The first simulation case shown in Fig. 3a considers the load turn-on (at $t=50 \mathrm{~ms}$ ) and turn-off (at $t=250 \mathrm{~ms}$ ) dynamics. The half-bridge operates at $50 \%$ fixed duty cycle and step-changes of $I_{L}=0 \rightarrow 100 \rightarrow 0 \mathrm{~A}$ are applied. The figure depicts the resulting voltage transient at the DC bus, showing that the current step-changes trigger the $L C$ resonance of the output filter, which are also observed at the front-end capacitor $C_{1}$. Hence, the turn-on and turn-off events cause oscillatory transients at $225 \mathrm{~Hz}$ with a magnitude of $5 \mathrm{~V}$. Secondly, if the load current exceeds a certain threshold, it may cause a permanent undervoltage in the network.

The second simulation case shown in Fig. 3b considers a $100 \mathrm{~Hz}$ fluctuating constant current load $I_{L}$ with an average value of $100 \mathrm{~A}$ and an magnitude of $20 \mathrm{~A}$. These power fluctuations cause voltage fluctuations across $C_{1}$, as depicted in the figure. Higher DC bus capacitors reduce the magnitude of the voltage fluctuations. The voltage waveform also includes switching ripple of $16 \mathrm{kHz}$, which can be considered as interharmonics as it has a discrete 
frequency spectrum. Of course, when multiple of these half-bridge converters would operate in parallel at different switching frequencies, the voltage ripple will have a continuous spectrum. The peak-peak voltage ripple in this case equals $q_{p p}=0.56 \%$ according to (3) and $q_{p p}=0.37 \%$ according to (4).

The third simulation case shown in Fig. $3 \mathrm{c}$ zooms in to three switching periods (the switching period equals $62.5 \mu \mathrm{s}$ ) and shows the voltage ripple in case the load current amounts $100 \mathrm{~A}$ continuously for two different capacitance values of $C_{1}=20 \mu \mathrm{F}$ and $C_{1}=1 \mathrm{mF}$. It demonstrates that a relatively small capacitance results into notches in the voltage waveform of $10 \mathrm{~V}$, corresponding to $\mathrm{RC}$ transient waveforms of repetitively charging and discharging $C_{1}$.

The fourth simulation case considers the NPC in Fig. 2b, interfacing a $230 \mathrm{~V} 50 \mathrm{~Hz}$ AC system to a $\pm 350 \mathrm{~V}$ bipolar DC system. As shown, the bipolar DC system contains two constant current sources connected between the positive-to-neutral and negative-to-neutral respectively. Fig. 3d depicts the simulation results for the two bus voltage $v_{p}$ and $v_{n}$ and both current sources set at $10 \mathrm{~A}$. The results exhibit a start-up transient and at $t=50 \mathrm{~ms}$ a step-change is applied to $I_{n}: 10 \rightarrow 14 \mathrm{~A}$. The simulation results present two DC power quality issues, namely imbalance and $150 \mathrm{~Hz}$ interharmonics.

\section{Conclusions}

This paper critically reviewed international power quality standards IEEE Std1159 and IEC 61000 in the light of DC microgrids. It is concluded that the majority of existing definitions of power quality are sufficiently general to encompass DC microgrids. Voltage transients, short- and long-term variations, noise, notching and voltage fluctuations are highly similar to the ex- 


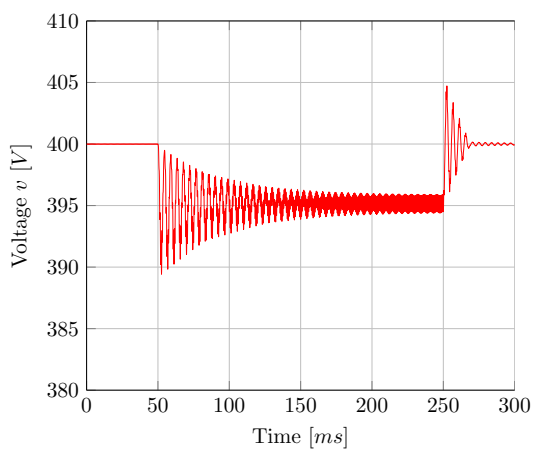

(a) Oscillatory load transient

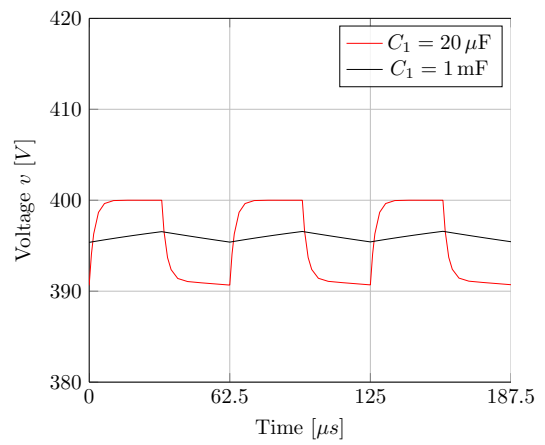

(c) Notching

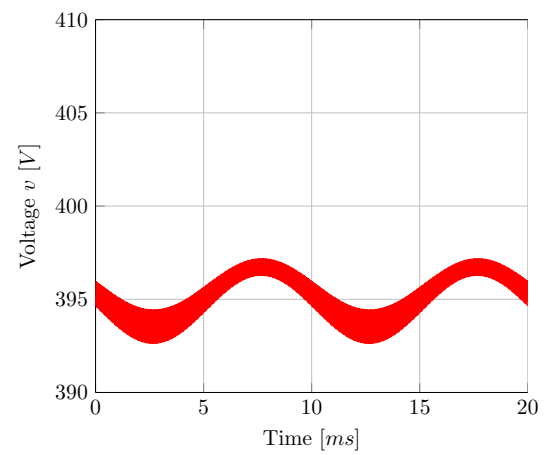

(b) Voltage fluctuation

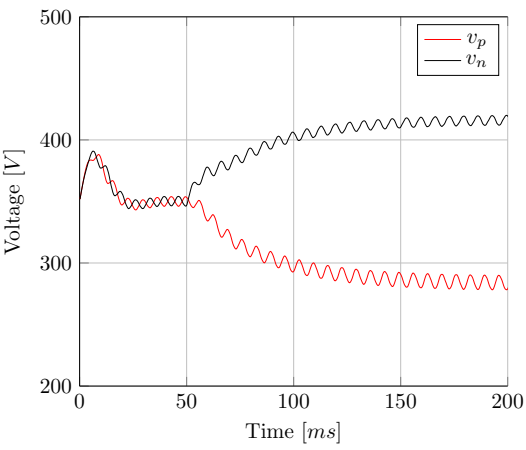

(d) Interharmonics and imbalance

Figure 3: Simulation results 
isting $\mathrm{AC}$ power quality issues. However the power quality issues $\mathrm{AC}$ offset, interharmonics and imbalance are clearly different. Furthermore, harmonics, DC offset and power frequency variations are by definition not present in DC microgrids. In bipolar DC microgrids voltage imbalance may occur and a voltage unbalance factor has been defined. However, a specific limit is not necessary, as other voltage constraints already ensure the functionality. The paper finally illustrated by simulation that power electronic converters can cause certain power quality issues which can be mitigated by appropriate filtering at the DC front-end. In general, it is anticipated that power quality issues in DC microgrids shift to higher frequencies as compared to $\mathrm{AC}$ because of the switch-mode operation of power electronic converters, the bandwidth of the controllers and the rapid fault dynamics.

\section{Acknowledgment}

G. Van den Broeck is funded by a PhD grant of the Research Foundation Flanders (FWO). J. Stuyts has a PhD Fellowship from VITO, the Flemish Institute for Technological Research. This project receives the support of the European Union, the European Regional Development Fund (ERDF), Flanders Innovation \& Entrepreneurship and the Province of Limburg.

\section{References}

[1] J. J. Justo, F. Mwasilu, J. Lee, J.-W. Jung, AC-microgrids versus DCmicrogrids with distributed energy resources: A review, Renewable and Sustainable Energy Reviews 24 (2013) 387 - 405. doi:http://dx.doi. org/10.1016/j.rser.2013.03.067. 
[2] D. L. Gerber, V. Vossos, W. Feng, C. Marnay, B. Nordman, R. Brown, A simulation-based efficiency comparison of AC and DC power distribution networks in commercial buildings, Applied Energy 210 (2018) 1167-1187. doi:10.1016/j.apenergy.2017.05.179.

[3] T. Hakala, T. Lhdeaho, P. Jrventausta, Low-Voltage DC distribution - utilization potential in a large distribution network company, IEEE Transactions on Power Delivery 30 (4) (2015) 1694-1701. doi:10. 1109/TPWRD . 2015.2398199.

[4] C. Capasso, O. Veneri, Experimental study of a DC charging station for full electric and plug in hybrid vehicles, Applied Energy 152 (2015) 131-142. doi:10.1016/J.APENERGY.2015.04.040.

[5] O. Veneri, C. Capasso, D. Iannuzzi, Experimental evaluation of DC charging architecture for fully-electrified low-power two-wheeler, Applied Energy 162 (2016) 1428-1438. doi:10.1016/J.APENERGY.2015. 03.138 .

[6] R. Noroozian, M. Abedi, G. B. Gharehpetian, S. H. Hosseini, Distributed resources and DC distribution system combination for high power quality, International Journal of Electrical Power and Energy Systems 32 (7) (2010) 769-781. doi:10.1016/j.ijepes.2010.01.013.

[7] D. Nilsson, A. Sannino, Efficiency analysis of low- and medium- voltage DC distribution systems, in: IEEE Power Engineering Society General Meeting, 2004., 2004, pp. 2315-2321 Vol.2. doi:10.1109/PES.2004. 1373299.

[8] S. Sanchez, M. Molinas, M. Degano, P. Zanchetta, Stability evalua- 
tion of a DC micro-grid and future interconnection to an AC system, Renewable Energy 62 (February) (2014) 649-656.

[9] B. Glasgo, I. L. Azevedo, C. Hendrickson, How much electricity can we save by using direct current circuits in homes? Understanding the potential for electricity savings and assessing feasibility of a transition towards DC powered buildings, Applied Energy 180 (2016) 66-75. doi : $10.1016 / j$.apenergy.2016.07.036.

[10] M. Mahdavyfakhr, N. Rashidirad, M. Hamzeh, K. Sheshyekani, E. Afjei, Stability improvement of DC grids involving a large number of parallel solar power optimizers: An active damping approach, Applied Energy 203 (2017) 364-372. doi:10.1016/j.apenergy.2017.06.044.

[11] A. Emadi, A. Khaligh, C. H. Rivetta, G. A. Williamson, Constant power loads and negative impedance instability in automotive systems: definition, modeling, stability, and control of power electronic converters and motor drives, IEEE Transactions on Vehicular Technology 55 (4) (2006) 1112-1125. doi:10.1109/TVT.2006.877483.

[12] O. Garcia, P. Zumel, A. de Castro, A. Cobos, Automotive DC-DC bidirectional converter made with many interleaved buck stages, IEEE Transactions on Power Electronics 21 (3) (2006) 578-586. doi:10. 1109/TPEL. 2006.872379.

[13] P. Nuutinen, A. Pinomaa, P. Peltoniemi, T. Kaipia, J. Karppanen, P. Silventoinen, Common-mode and RF EMI in a low-voltage DC distribution network with a pwm grid-tie rectifying converter, IEEE Transactions on Smart Grid 8 (1) (2017) 400-408. doi:10.1109/TSG.2016. 2602845 . 
[14] M. C. Magro, A. Mariscotti, P. Pinceti, Definition of power quality indices for DC low voltage distribution networks, in: 2006 IEEE Instrumentation and Measurement Technology Conference Proceedings, 2006, pp. 1885-1888. doi:10.1109/IMTC.2006.328304.

[15] A. Mariscotti, Methods for ripple index evaluation in DC low voltage distribution networks, in: 2007 IEEE Instrumentation Measurement Technology Conference IMTC 2007, 2007, pp. 1-4. doi : 10.1109/IMTC. 2007.379205

[16] S. Whaite, B. Grainger, A. Kwasinski, Power Quality in DC Power Distribution Systems and Microgrids, Energies 8 (5) (2015) 4378-4399. doi:10.3390/en8054378.

[17] International Electrotechnical Comission, IEC 61000-4-30: Electromagnetic compatibility (EMC) - Part 4-30: Testing and measurement techniques - Power quality measurement methods., Tech. rep., International Electrotechnical Comission (2001).

[18] M. H. Bollen, Understanding power quality problems, Wiley-IEEE Press, 2000.

[19] R. Dugan, M. McGranaghan, Electrical power systems quality, McGraw-Hill, New York, 1996.

[20] IEEE Standards Association, IEEE Std1100-2005 - IEEE Recommended Practice for Powering and Grounding Electronic Equipment, Institute of Electrical and Electronics Engineers, 2005. doi:10.1109/ IEEESTD.2006.216391, 
[21] IEEE Recommended Practice for $1 \mathrm{kV}$ to $35 \mathrm{kV}$ Medium-Voltage DC Power Systems on Ships, 2010. doi:10.1109/IEEESTD.2010.5623440.

[22] IEEE Standards Association, IEEE Std 1159 - IEEE Recommended Practice for Monitoring Electric Power Quality (Jun. 2009). doi:10. 1109/IEEESTD. 2009.5154067.

[23] B. Singh, A. Chandra, K. Al-Haddad, Power quality: problems and mitigation techniques, John Wiley \& Sons, 2014.

[24] EN 50160, Voltage characteristics of electricity supplied by public electricity networks, 2010.

[25] Suomen Standardisoimisliitto, SFS 6000 Sähköasennusstandardisarja, 2017.

[26] H. Kakigano, Y. Miura, T. Ise, Low-voltage bipolar-type DC microgrid for super high quality distribution, IEEE Transactions on Power Electronics 25 (12) (2010) 3066-3075. doi:10.1109/TPEL. 2010.2077682.

[27] G. Van den Broeck, S. De Breucker, J. Beerten, M. Dalla Vecchia, J. Driesen, Analysis of Three-Level Converters with Voltage Balancing Capability in Bipolar DC Distribution Networks, in: International Conference on DC Microgrids, 2017, pp. 248-255.

[28] Y. Gu, W. Li, X. He, Analysis and control of bipolar LVDC grid with DC symmetrical component method, IEEE Transactions on Power Systems 31 (1) (2016) 685-694. doi:10.1109/TPWRS.2015.2403310.

[29] IEEE Standards Association, IEEE Recommended Practice for Electric Power Distribution for Industrial Plants, 1994. doi:10.1109/IEEESTD. 1994.121642. 
[30] VDA Empfehlung 320, Elektrische und elektronische Komponenten im Kraftfahrzeug 48V-Bordnetz (2014).

[31] IEEE, 519-2014 IEEE Recommended Practice and Requirements for Harmonic Control in Electric Power Systems., 2014.

[32] A. Bindra, Wide-bandgap power devices: Adoption gathers momentum, IEEE Power Electronics Magazine 5 (1) (2018) 22-27. doi:10.1109/ MPEL.2017.2782404,

[33] E. Hoene, G. Deboy, C. R. Sullivan, G. Hurley, Outlook on developments in power devices and integration: Recent investigations and future requirements, IEEE Power Electronics Magazine 5 (1) (2018) 2836. doi:10.1109/MPEL.2017.2782398.

[34] L. Tan, B. Wu, V. Yaramasu, S. Rivera, X. Guo, Effective Voltage Balance Control for Bipolar-DC-Bus-Fed EV Charging Station With Three-Level DCDC Fast Charger, IEEE Transactions on Industrial Electronics 63 (7) (2016) 4031-4041. doi:10.1109/TIE.2016.2539248.

[35] M. Albu, E. Kyriakides, G. Chicco, M. Popa, A. Nechifor, Online monitoring of the power transfer in a DC test grid, IEEE Transactions on Instrumentation and Measurement 59 (5) (2010) 1104-1118. doi:10.1109/TIM.2010.2045147.

[36] R. Ghandehari, A. Shoulaie, Evaluating voltage notch problems arising from ac/DC converter operation, IEEE Transactions on Power Electronics 24 (9) (2009) 2111-2119. doi:10.1109/TPEL.2009.2021058.

[37] International Electrotechnical Commission, IEC61000-2-2 Environment 
- Compatibility levels for low-frequency conducted disturbances and signalling in public low-voltage power supply systems, 2002.

[38] A. J. Roscoe, S. J. Finney, G. M. Burt, Tradeoffs between ac power quality and DC bus ripple for 3-phase 3-wire inverter-connected devices within microgrids, IEEE Transactions on Power Electronics 26 (3) (2011) 674-688. doi:10.1109/TPEL.2011.2105892.

[39] IEC 61000-4-15, Electromagnetic compatibility (EMC) - Part 4-15: Testing and measurement techniques - Flickermeter - Functional and design specifications, 2010.

[40] L. Kukacka, P. Dupuis, G. Zissis, J. Kraus, M. Kolar, Extra low voltage DC grid led lighting systems: photometric flicker analysis, in: 2015 IEEE International Workshop of Electronics, Control, Measurement, Signals and their Application to Mechatronics (ECMSM), 2015, 6 pages. doi:10.1109/ECMSM.2015.7208692. 